\title{
Work Intensity, Low-Grade Inflammation, and Oxidative Status: A Comparison between Office and Slaughterhouse Workers
}

\author{
Sieglinde Zelzer (D), ${ }^{1}$ Franz Tatzber, ${ }^{2}$ Markus Herrmann, ${ }^{1}$ Willibald Wonisch (D), ${ }^{3}$ \\ Stefan Rinnerhofer, ${ }^{4}$ Michael Kundi, ${ }^{5}$ Barbara Obermayer-Pietsch, ${ }^{6}$ Tobias Niedrist, ${ }^{1}$ \\ Gerhard Cvirn, ${ }^{3}$ Georg Wultsch, ${ }^{7}$ and Harald Mangge ${ }^{1}$ \\ ${ }^{1}$ Clinical Institute of Medical and Chemical Laboratory Diagnostics, Medical University of Graz, Auenbruggerplatz 29, \\ 8036 Graz, Austria \\ ${ }^{2}$ Center of Molecular Medicine, Institute of Pathophysiology and Immunology, Medical University of Graz, Heinrichstrasse 31a, \\ 8010 Graz, Austria \\ ${ }^{3}$ Institute of Physiological Chemistry, Center for Physiological Medicine, Medical University of Graz, Stiftingtalstrasse 6 M1/D/3, \\ 8036 Graz, Austria \\ ${ }^{4}$ Exercise Physiology, Training and Training Therapy Research Group, Institute of Sports Science, University of Graz, Mozartgasse 14, \\ 8010 Graz, Austria \\ ${ }^{5}$ Department of Environmental Health, Center for Public Health, Medical University Vienna, Kinderspitalgasse 15, \\ 1090 Vienna, Austria \\ ${ }^{6}$ Division of Endocrinology and Diabetology, Department of Internal Medicine, Medical University of Graz, Auenbruggerplatz 15, \\ 8036 Graz, Austria \\ ${ }^{7}$ Arbeitsmedizinisches Institut, Graz, Herrgottwiesgasse 149, 8055 Graz, Austria
}

Correspondence should be addressed to Sieglinde Zelzer; sieglinde.zelzer@klinikum-graz.at

Received 15 December 2017; Accepted 11 March 2018; Published 18 April 2018

Academic Editor: Grzegorz Bartosz

Copyright @ 2018 Sieglinde Zelzer et al. This is an open access article distributed under the Creative Commons Attribution License, which permits unrestricted use, distribution, and reproduction in any medium, provided the original work is properly cited.

\begin{abstract}
Limited knowledge exists about the impact of physical workload on oxidative stress in different occupational categories. Thus, we aimed to investigate the oxidative and inflammatory status in employees with different physical workloads. We enrolled a total of 79 male subjects, 27 office workers (mean age $38.8 \pm 9.1$ years) and 52 heavy workers, in a slaughterhouse (mean age $40.8 \pm 8.2$ years). Fasting blood was drawn from an antecubital vein in the morning of the midweek before an 8-hour or 12-hour work shift. The antioxidative capacity was assessed measuring total antioxidant capacity (TAC), uric acid, total polyphenols (PPm), and endogenous peroxidase activity (EPA). Total peroxides (TOC), malondialdehyde (MDA), and myeloperoxidase (MPO) were analyzed as prooxidative biomarkers, and an oxidative stress index (OSI) was calculated. In addition, hsCRP, interleukin-6 (IL-6), MDA-LDL IgM antibodies, galectin-3, adrenocorticotropic hormone (ACTH), and the brain-derived neurotrophic factor (BDNF) were measured as biomarkers of chronic systemic inflammation and emotional stress. TOC $(p=0.032)$, TAC $(p<0.001)$, ACTH $(p<0.001)$, OSI $(p=0.011)$, and hsCRP $(p=0.019)$ were significantly increased in the heavy workers group, while EPA, BDNF $(p<0.001)$, and polyphenols $(p=0.004)$ were significantly higher in office workers. Comparison between 8 and $12 \mathrm{~h}$ shifts showed a worse psychological condition in heavy workers with increased levels for hsCRP $(p=0.001)$ and reduced concentration of BDNF $(p=0.012)$ compared to office workers. Oxidative stress and inflammation are induced in heavy workers and are particularly pronounced during long working hours, that is, 12-hour versus 8-hour shifts.
\end{abstract}




\section{Introduction}

Modern life-style, that is, physical inactivity and fast food as well as occupational and environmental conditions, may induce oxidative stress. Different types of stress can be distinguished at the cellular and tissue level-namely, photooxidative stress, drug-dependent oxidative stress, metabolic oxidative stress, environmental oxidative stress, and nitrosative stress [1].

Reactive oxygen species (ROS) are endogenously generated, among others, in the respiratory chain. Hence, metabolic activity increases ROS production. These species react with biological molecules like lipids, carbohydrates, proteins, and even DNA, which are associated with the pathogenesis of degenerative diseases. Oxidative stress (OS) is associated with chronic inflammation, with a potential impact on diabetes mellitus, atherosclerosis, and cardiovascular and neurodegenerative diseases [2-5]. An increased consumption of oxygen during physical exercise also increases ROS production leading to oxidative stress and lipid peroxidation in athletes [6-8]. Nevertheless, increased ROS production during sports is also beneficial because it stimulates the antioxidative system [9]. Moreover, OS is a key factor during aging [10] together with other factors like deregulated autophagy, mitochondrial dysfunction, and telomere shortening [11]. Besides its involvement in the physiologic process of aging, OS appears to play an important role in the pathophysiology of several occupational diseases $[12,13]$. Common problems in night and shift workers, such as fatigue, sleep problems, anxiety, difficulties in maintaining regular life-styles, and reduced recovery times, represent an increased health risk due to physiological exhaustion and a decreased capacity for regulation [14].

Nevertheless, there is limited knowledge about the impact of physical workload on OS in different occupational groups. Heavy workers often suffer from excessive workload and lack of social support. Shift work with extended working hours might negatively affect the psychological status of employees and reduce their motivation. It can be hypothesized that high physical and emotional stress in heavy workers is associated with increased OS and inflammation.

The present study aimed at comparing the oxidative and inflammatory status between office workers and heavy workers with a particular focus on the biochemical effect of extended working hours (8- to 12-hour shifts).

\section{Materials and Methods}

2.1. Study Population. We enrolled 79 healthy male volunteers between 18 and 65 years at their workplace. Thereof, 27 employees were office workers (age 38.8 \pm 9.1 years) and 52 heavy workers in a slaughterhouse (age $40.8 \pm 8.2$ years). Exclusion criteria were infections, for example, flu-like infection, chronic diseases, and certified reduced work capacity due to illness. The study was approved by the ethics committee of the Medical University of Graz (EK number 26-488 ex 13/14) and conducted in compliance with guidelines for human studies as described in the Helsinki Declaration of 1975, revised in 1996. Written inform consent was obtained from all study participants.

\subsection{Laboratory Analysis}

2.2.1. Blood Sampling. Blood was drawn from an antecubital vein between 6:00 a.m. and 6:30 a.m., before an 8-hour work shift from 79 workers (27 office and 52 heavy workers). In a subgroup of 26 office workers and 8 heavy workers, we investigated the effects of twelve hours of work. Blood sampling was performed in the midweek, Wednesdays or Thursdays. Samples were immediately transferred on ice to the Lab within two hours, centrifuged, and stored at $-80^{\circ} \mathrm{C}$ until use (6 to 13 months).

2.2.2. Inflammatory Parameters. High-sensitivity C-reactive protein (hsCRP) and interleukin 6 (IL-6) were determined on a $\mathrm{COBAS}^{\circledR} 8000$ analyzer with turbidimetric and electrochemiluminescence immunoassays (ECLIA), respectively, from Roche Diagnostics (Rotkreuz, Switzerland). All measurements were batched into a single run. The total imprecision of both assays were below 5\%. Galectin-3 was measured using the Human Galectin-3 Quantikine ELISA Kit from R\&D (Minneapolis, USA).

2.2.3. Oxidative Stress Biomarkers. Malondialdehyde (MDA) was determined by GC-MS from Thermo Fisher Scientific (CA, USA). After addition of MDA-d 2 as internal standard, derivatization with 2,4-dinitrophenylhydrazine, and chemical ionization in negative mode, the representative ions $\mathrm{m} / z 204$ (for MDA) and $m / z 206$ (for MDA-d 2) were recorded [15].

Colorimetric methods were used to determine total peroxides (TOC), endogenous peroxidase activity (EPA), and the total antioxidant capacity (TAC) purchased from LDN (Labor Diagnostika Nord, Nordhorn, Germany). These assays are based on the reaction between hydrogen peroxide, horseradish peroxidase, and tetramethylbenzidine to give a bluegreen colour. After the addition of the stop solution, the colour changes to yellow, which can be measured at $450 \mathrm{~nm}$ (reference wavelength $620 \mathrm{~nm}$ ). A linear standard curve was used for quantification. The intra- and interassay coefficients of variance were less than 5\% for all assays [16]. MDA-LDL IgM was measured with the MDA-LDL-IgM ELISA from Omnignostica Ltd. (Höflein/D., Austria), which is standardized on a human monoclonal antibody as described previously [17]. Serum myeloperoxidase (MPO) concentrations were measured with the MPO enzyme-linked immunosorbent assay (ELISA) Kit (Immundiagnostik AG, Bensheim, Germany) according to the manufacturer's instructions. The total imprecision of both ELISA assays was below 7\%. Uric acid was determined with the enzymatic colorimetric test from Roche on a COBAS 8000 analyzer.

In the case of the brain-derived neurotrophic factor (BDNF), we used the Quantikine human BDNF immunoassay from R\&D systems (Minneapolis, USA). Adrenocorticotropic hormone $(\mathrm{ACTH})$ was determined with the ACTH ELISA from Hölzel Diagnostica (Köln, Germany), and total polyphenols (PPm) were determined according to the manufacturer's instructions with an adapted Folin-Ciocalteu microtitre method from Omnignostica Ltd. (Höflein/D., Austria). In short, the principle of this method is based on the reaction of polyphenols with transition metals. This leads 
TABLE 1: Baseline characteristics of study participants and results of measurements after an 8-hour work shift.

\begin{tabular}{|c|c|c|c|}
\hline & Office workers $(n=27)$ & Heavy workers $(n=52)$ & \\
\hline & Mean $(9$ & interval) & $p$ \\
\hline Age, yrs & $38.2(35.2-41.1)$ & $40.8(38.5-43.0)$ & 0.175 \\
\hline Body mass index, $\mathrm{kg} / \mathrm{m}^{2}$ & $26.1(24.5-27.6)$ & $28.3(27.1-29.5)$ & 0.026 \\
\hline hsCRP, mg/L & $1.0(0.7-1.5)$ & $1.7(1.4-2.2)$ & 0.019 \\
\hline IL-6, pg/mL & $1.9(1.6-2.2)$ & $2.0(1.7-2.2)$ & 0.220 \\
\hline Uric acid, mg/dL & $5.3(4.8-5.7)$ & $5.6(5.3-5.9)$ & 0.245 \\
\hline Total antioxidant capacity, mmol/L & $1.06(0.91-1.21)$ & $1.41(1.29-1.53)$ & $<0.001$ \\
\hline Total oxidant capacity, mmol/L & $0.08(0.06-0.11)$ & $0.12(0.10-0.15)$ & 0.032 \\
\hline Oxidative stress index (OSI), \% & $5.7(3.5-8.4)$ & $10.4(8.2-12.8)$ & 0.011 \\
\hline Endogenous peroxidase activity, U/L & $7.2(6.2-8.4)$ & $3.7(3.3-4.1)$ & $<0.001$ \\
\hline Polyphenols, mmol/L & $9.9(9.7-10.1)$ & $9.5(9.4-9.7)$ & 0.004 \\
\hline Malondialdehyde, $\mu \mathrm{mol} / \mathrm{L}$ & $0.74(0.68-0.80)$ & $0.69(0.65-0.73)$ & 0.144 \\
\hline Myeloperoxidase, $\mu \mathrm{g} / \mathrm{L}$ & $61.7(56.4-67.4)$ & $68.3(63.7-73.2)$ & 0.078 \\
\hline MDA-LDL-IgM, U/L & $184(149-228)$ & $150(127-177)$ & 0.141 \\
\hline $\mathrm{ST} 2, \mathrm{ng} / \mathrm{mL}$ & $14.5(12.3-16.6)$ & $15.3(13.7-17.0)$ & 0.521 \\
\hline $\mathrm{ACTH}, \mathrm{pg} / \mathrm{mL}$ & $12.0(9.1-16.0)$ & $27.6(22.2-34.4)$ & $<0.001$ \\
\hline Galectin-3, ng/mL & $5.9(5.0-6.9)$ & $4.8(4.2-5.4)$ & 0.052 \\
\hline BDNF, pg/mL & $22880(16051-32616)$ & 7417 (5651-9735) & $<0.001$ \\
\hline
\end{tabular}

$p$ values from the general linear model with body mass index included as covariate. hsCRP = high-sensitivity C-reactive protein; IL- $6=$ interleukin- 6 OSI = oxidative stress index; ACTH = adrenocorticotropic hormone; $\mathrm{ST} 2=$ suppression of tumorigenicity 2; $\mathrm{BDNF}=$ brain-derived neurotrophic factor.

to a dark-coloured complex, which can be measured at $766 \mathrm{~nm}$. Samples are quantified by the use of a standard curve with serial dilutions of a polyphenol standard. The intra- and interassay coefficients of variance were less than $5 \%$.

2.3. Statistical Analysis. Statistical analyses were carried out using SPSS 23.0 for Windows 10 (IBM Corp., USA) and Stata 12 (StataCorp, TX, USA). Comparisons between groups were done by the use of the general linear model including body mass index (BMI) as a covariate because heavy workers had significantly higher BMI which itself could be related to oxidative stress and inflammation, as reported previously [18]. Residuals of analyses were stored and tested for deviations from a normal distribution by Kolmogorov-Smirnov tests with Lilliefors-corrected $p$ values. In case of a significant deviation, distribution of residuals was inspected, and in case of a skewed distribution, a logarithmic transformation was applied. In all such cases, normality of residuals was obtained after transformation. Homogeneity of variance was tested by Levene's tests. Data are summarized as means within groups and $95 \%$ confidence intervals (back-transformed if necessary to the original scale). A similar approach was applied for comparison of $8 \mathrm{~h}$ versus $12 \mathrm{~h}$ shifts. In this case, the within-subject factor $(8 \mathrm{~h} / 12 \mathrm{~h}$ shift length) and betweensubject factor groups (office versus heavy workers) and their interaction were tested by analysis of variance. Comparisons of $8 \mathrm{~h}$ and $12 \mathrm{~h}$ shifts within groups were done by linear contrasts. Variables were log-transformed in accordance with the analysis of baseline data. Based on the ratio between ROS and serum antioxidant capacity, the oxidative stress index (OSI) was calculated using the formula (TOC $[\mathrm{mmol} / \mathrm{L}] / \mathrm{TA}$
$\mathrm{C}[\mathrm{mmol} / \mathrm{L}] \times 100)$. For all statistical tests, $p<0.05$ was considered significant.

\section{Results}

An overview about the anthropometric data of the study cohort is given in Table 1. Due to the fact that the BMI was significantly increased in heavy workers versus office workers, all further analyses were corrected with respect to this biometric parameter, because BMI itself was shown to be associated with OS [18].

Heavy workers had significantly increased TAC $(p<$ $0.001)$, TOC $(p=0.032)$, hsCRP $(p=0.019)$, and ACTH $(p<0.001)$ (for details, see Figures 1 and 2 and Table 1) and OSI levels $(p=0.011$; Table 1$)$. In contrast, EPA $(p<$ $0.001)$, polyphenols $(p=0.004)$, and BDNF $(p<0.001)$ levels were significantly higher in office workers (Figures 3 and 4). Uric acid, MDA, MPO, IL-6, MDA-LDL IgM, and galectin3 did not differ between the groups (Table 1).

Comparison between 8-hour and 12-hour shifts revealed significant differences exclusively after a 12-hour shift in heavy workers, that is, a significant increased ACTH level $(p=0.001)$, while BDNF was significantly decreased at overtime work $(p=0.012)$ (Table 2). Correlation analysis between oxidative stress biomarkers revealed a significant negative correlation between TAC and EPA in both working groups whereas a positive correlation was found for TAC and uric acid (Table 3). TOC correlated positively with hsCRP in both working groups $(r=0.612$ and 0.493 in office and heavy workers, resp.). In contrast, IL- 6 was correlated to TOC merely in office workers $(r=0.462)$, while the 


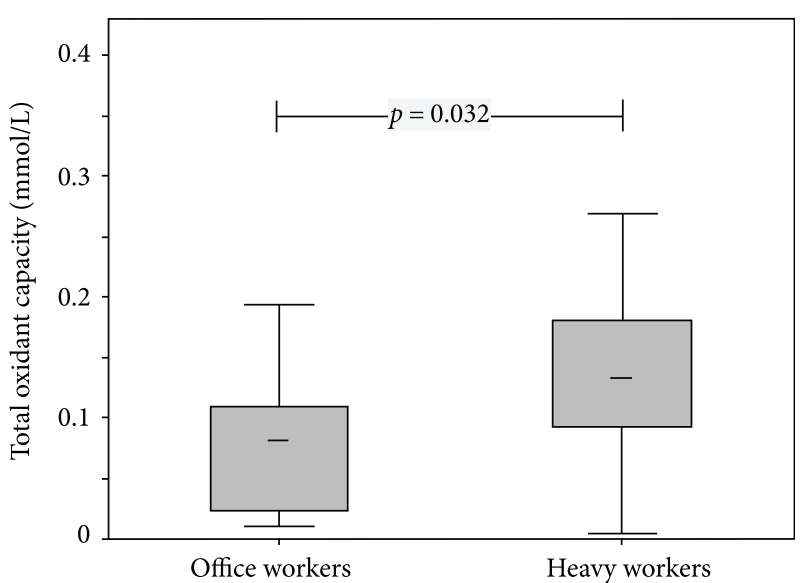

Figure 1: Box plots (medians, interquartile, and nonoutlier ranges) of total oxidant capacity by groups of workers.

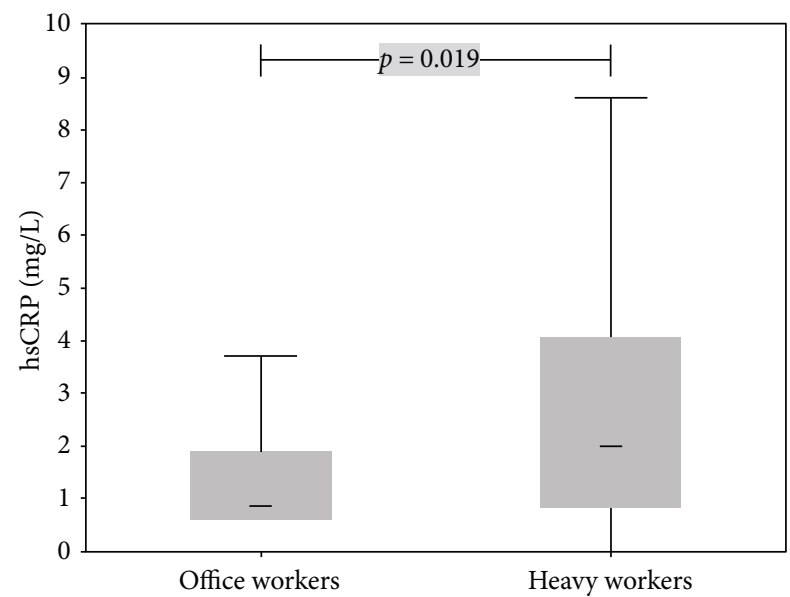

Figure 2: Box plots (medians, interquartile, and nonoutlier ranges) of hsCRP by groups of workers.

correlation with polyphenols was only significant in heavy workers $(r=0.565)$. Furthermore, TAC showed a highly significant negative correlation with TOC in office workers $(r=-0.526)$ (Table 3$)$.

\section{Discussion}

In the present study, we indicated an increased inflammation through raised hsCRP levels at baseline in heavy workers compared to office workers. This was associated with oxidative stress, that is, increased total peroxides and a concomitant decrease of peroxidase activity. In addition, we observed a decrease in polyphenols, although the total antioxidant capacity was increased (Table 1). OSI, which reflects the redox balance between prooxidants and antioxidants, showed significant differences between these two working groups.

This was further related to psychological stress, due to an increase in ACTH and a very low level of BDNF indicating emotional stress (Table 1). In spite of significant differences

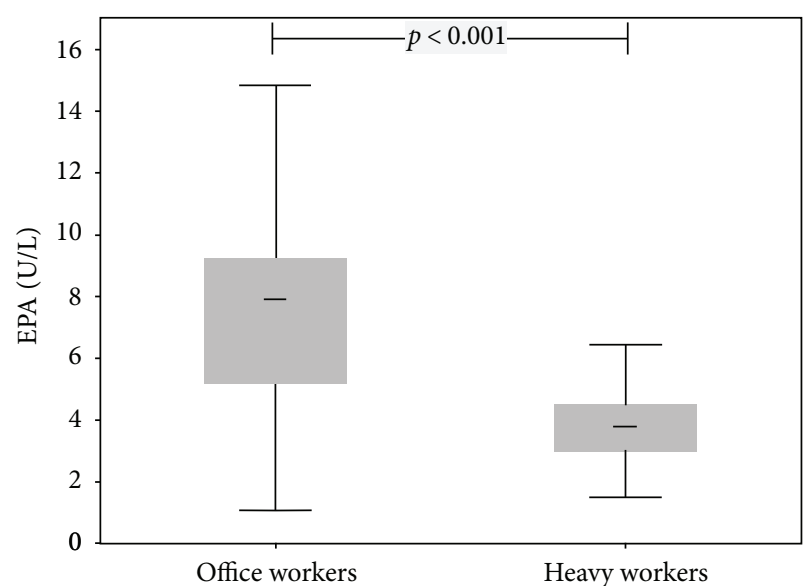

Figure 3: Box plots (medians, interquartile, and nonoutlier ranges) of endogenous peroxidase activity by groups of workers.

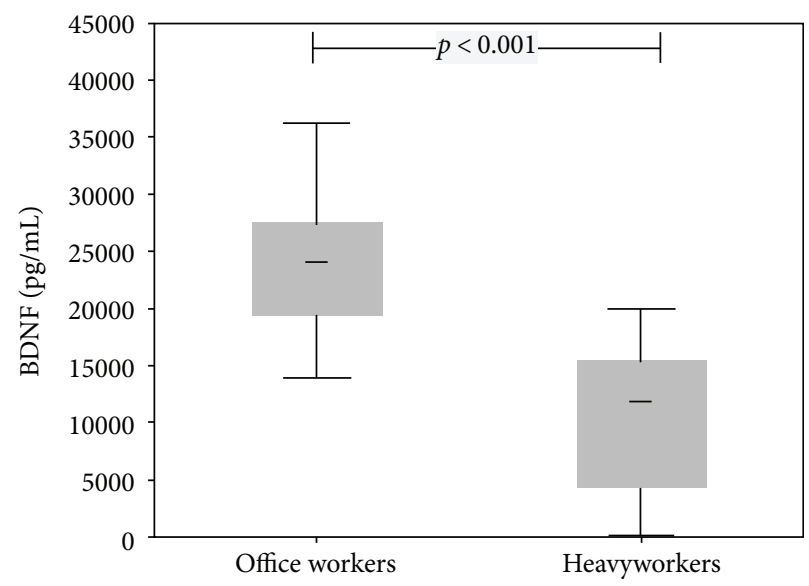

FIgURE 4: Box plots (medians, interquartile, and nonoutlier ranges) of brain-derived neurotrophic factor by groups of workers.

in several biomarkers between office workers and heavy workers in a slaughterhouse, it must be emphasized that this might even be an underestimation due to the working environment of the latter; that is, low temperatures were previously associated with reduced OS $[19,20]$.

A stressful working environment may affect the health of employees. Night shifts disrupt the circadian rhythm and increase OS [21]. There can be no doubt that a better understanding of the main stressors in the workplace would be effective in preventing disease and that determination of oxidative stress biomarkers could be helpful in this context [7]. Since reduction of sickness-related absenteeism implies economic benefits, individual health care at the workplace should be given priority. Increased disease risks in workers with demanding jobs have frequently been reported, among others by Ramey et al. [22]. Release of catecholamines and increased blood pressure, along with chronic work-related stress, may lead to cardiovascular diseases. A combination of psychological and physical stress could induce chronic inflammation and subsequent disease [23]. For such reasons, a dietary regimen including antioxidants was suggested 
TABLE 2: Comparison of stress and inflammatory biomarkers between 8 and $12 \mathrm{~h}$ shifts in office and heavy workers.

\begin{tabular}{|c|c|c|c|c|c|c|}
\hline & \multicolumn{3}{|c|}{ Office workers $(n=26)$} & \multicolumn{3}{|c|}{ Heavy workers $(n=8)$} \\
\hline & $\begin{array}{c}\text { After } 8 \text { hours } \\
\text { Mean }(95 \% \mathrm{CI})\end{array}$ & $\begin{array}{c}\text { After } 12 \text { hours } \\
\text { Mean }(95 \% \text { CI })\end{array}$ & $p$ & $\begin{array}{c}\text { After } 8 \text { hour } \\
\text { Mean }(95 \% \text { CI })\end{array}$ & $\begin{array}{c}\text { After } 12 \text { hour } \\
\text { Mean }(95 \% \text { CI })\end{array}$ & $p$ \\
\hline hsCRP, mg/L & $1.23(0.89-1.71)$ & $1.08(0.82-1.43)$ & 0.311 & $0.98(0.54-1.79)$ & $0.84(0.50-1.39)$ & 0.482 \\
\hline IL-6, pg/mL & $1.89(1.57-2.28)$ & $1.71(1.51-1.93)$ & 0.350 & $1.79(1.27-2.53)$ & $1.97(1.57-2.46)$ & 0.641 \\
\hline $\begin{array}{l}\text { Total antioxidant capacity, } \\
\mathrm{mmol} / \mathrm{L}\end{array}$ & $1.03(0.81-1.25)$ & $1.20(0.94-1.46)$ & 0.236 & $1.26(0.91-1.61)$ & $0.98(0.56-1.40)$ & 0.220 \\
\hline Total oxidant capacity, $\mathrm{mmol} / \mathrm{L}$ & $0.10(0.07-0.16)$ & $0.10(0.07-0.15)$ & 0.786 & $0.05(0.02-0.10)$ & $0.07(0.03-0.14)$ & 0.110 \\
\hline $\begin{array}{l}\text { Endogenous peroxidase } \\
\text { activity, U/L }\end{array}$ & $6.54(5.12-8.36)$ & $7.23(6.21-8.43)$ & 0.434 & $8.00(5.40-11.86)$ & $8.00(6.26-10.23)$ & 0.998 \\
\hline Malondialdehyde, $\mu \mathrm{mol} / \mathrm{L}$ & $0.72(0.64-0.80)$ & $0.75(0.65-0.86)$ & 0.610 & $0.79(0.64-0.96)$ & $0.76(0.59-0.98)$ & 0.857 \\
\hline Myeloperoxidase, $\mu \mathrm{mol} / \mathrm{L}$ & $65.9(55.0-78.8)$ & $67.5(59.0-77.4)$ & 0.812 & $64.5(46.4-89.7)$ & $56.3(43.9-72.2)$ & 0.488 \\
\hline Paraoxonase, ng/mL & $14.6(13.1-16.2)$ & $14.2(12.9-15.5)$ & 0.441 & $12.7(10.4-15.4)$ & $11.5(9.8-13.6)$ & 0.171 \\
\hline $\mathrm{ACTH}, \mathrm{pg} / \mathrm{mL}$ & $12.2(7.7-19.4)$ & $13.6(10.3-18.0)$ & 0.510 & $8.8(3.8-20.5)$ & $24.9(15.0-41.4)$ & 0.001 \\
\hline BDNF, pg/mL & $24030(21661-26658)$ & $22941(20777-25330)$ & 0.479 & $24634(20370-29790)$ & $17921(14947-21485)$ & 0.012 \\
\hline
\end{tabular}

$p$ values from linear contrasts after analysis of variance with body mass index included as a covariate.

TABLE 3: Spearman correlation coefficients between stress and inflammation biomarkers.

\begin{tabular}{lcccccccc}
\hline & \multicolumn{2}{c}{ TAC } & \multicolumn{2}{c}{ TOC } & \multicolumn{2}{c}{ EPA } & \multicolumn{2}{c}{ Polyphenols } \\
& $\begin{array}{c}\text { Office } \\
\text { workers } \\
(n=27)\end{array}$ & $\begin{array}{c}\text { Heavy } \\
\text { workers } \\
(n=52)\end{array}$ & $\begin{array}{c}\text { Office } \\
\text { workers } \\
(n=27)\end{array}$ & $\begin{array}{c}\text { Heavy } \\
\text { workers } \\
(n=52)\end{array}$ & $\begin{array}{c}\text { Office } \\
\text { workers } \\
(n=27)\end{array}$ & $\begin{array}{c}\text { Heavy } \\
\text { workers } \\
(n=52)\end{array}$ & $\begin{array}{c}\text { Office } \\
\text { workers } \\
(n=27)\end{array}$ & $\begin{array}{c}\text { Heavy } \\
\text { workers } \\
(n=52)\end{array}$ \\
\hline hsCRP & -0.181 & 0.217 & $0.612^{* * *}$ & $0.493^{* * *}$ & 0.172 & -0.074 & -0.132 & $0.290^{*}$ \\
IL-6 & -0.219 & 0.167 & $0.462^{*}$ & 0.168 & 0.228 & -0.069 & -0.098 & 0.033 \\
Uric acid & $0.506^{* *}$ & $0.516^{* * *}$ & -0.105 & -0.001 & -0.343 & -0.069 & -0.083 & 0.218 \\
TAC & & & $-0.526^{* *}$ & -0.058 & $-0.648^{* * *}$ & $-0.633^{* * *}$ & -0.164 & 0.075 \\
TOC & $-0.526^{* *}$ & -0.058 & & & 0.184 & -0.196 & 0.123 & $0.565^{* * *}$ \\
EPA & $-0.648^{* * *}$ & $-0.633^{* * *}$ & 0.184 & -0.196 & & -0.160 & $-0.292^{*}$ \\
Polyphenols & -0.164 & 0.075 & 0.123 & $0.565^{* * *}$ & -0.160 & $-0.292^{*}$ & -0.097 & -0.050 \\
MPO & 0.177 & 0.152 & 0.075 & 0.010 & -0.093 & -0.097 & -0.112 \\
Paraoxonase & 0.206 & 0.075 & 0.106 & -0.154 & -0.249 & -0.221 & 0.040 \\
ACTH & -0.042 & 0.059 & -0.026 & -0.096 & -0.014 & -0.031 & 0.129 \\
BDNF & -0.001 & 0.048 & 0.121 & -0.003 & -0.014 & -0.072 & 0.016 \\
\hline
\end{tabular}

${ }^{*} p<0.05,{ }^{* *} p<0.01$, and ${ }^{* * *} p<0.001$. hsCRP $=$ high-sensitivity C-reactive protein; IL- $6=$ interleukin-6; TAC = total antioxidant capacity; TOC $=$ total oxidant capacity; $\mathrm{EPA}=$ endogenous peroxidase activity; $\mathrm{MPO}=$ myeloperoxidase; $\mathrm{ACTH}=$ adrenocorticotropic hormone; $\mathrm{BDNF}=$ brain-derived neurotrophic factor.

$[24,25]$, but it is not clear if such a strategy is of much help [26], especially if the working conditions otherwise remain unchanged.

Notably, sensitive biomarkers identified these effects, pointing to early development of an imbalance in the redox system. Nevertheless, there were no changes in MDA, one of the end products of lipid peroxidation, MDA-LDL IgM, a biomarker for immune activation, MPO, uric acid, and galectin-3. Although the significant differences seen between occupational groups were fluctuations within "normal" ranges, it must be kept in mind that individuals may be exposed to these changes throughout their working lives. Such mild chronic stress responses over prolonged time periods are in line with our results and were also reported in an animal experiment with increased oxidative stress and consumption of antioxidants, especially in the pancreas. This led to systemic inflammation and contributed to degenerative diseases [27].

It was striking that overtime was accompanied by an almost threefold increase of ACTH and a significant decrease in BDNF in laborers only (Table 2), pointing to a combined impact of a heavy workload and $12 \mathrm{~h}$ shift.

Overtime, shift work [23] and extended exposure to occupational and environmental stressors diminish antioxidative capacity, which may elevate the impact of increased production of OS due to a heavy workload [28, 29]. Walker et al. [30] reported that inflammation and alterations of the immune system were associated with altered mood and reduced well-being, thus highlighting the need for improved risk management in the workplace. 
We observed a significant correlation between the total antioxidant capacity and uric acid, as has been reported previously [18]. There is also a strong inverse correlation between endogenous peroxidase activity and total antioxidant capacity. The correlation between (hsCRP) and oxidative stress (TOC) underlines the link between inflammation and cellular stress responses (Table 3).

Monitoring with sensitive biomarkers may be advisable, particularly in cases of smoking, obesity, and older age, to counteract an accumulation of stress-related biological changes that could have adverse health effects. Research of oxidative stress under real-life working conditions is a win-win situation for both employers and employees. It could help to tailor health care and counseling for workers, minimizing sickness absenteeism and reducing fluctuation in the workforce.

The small number of manual laborers doing a 12-hour work shift could be a limitation for this study due to insufficient compliance. In addition, the lack of female subjects is a constraint of this work. Therefore, further research in these working groups with a larger collective, including female workers, should be performed.

In conclusion, we found increased oxidative stress and inflammation in manual laborers as compared to office workers. Indications of psychological stress were observed for overtime work in combination with hard physical work. The relationship between antioxidant consumption, oxidative stress, and inflammation was clearly shown in the correlation analysis. These data provide a solid basis for further research on this important subject with a larger collective.

\section{Abbreviations}

$\begin{array}{ll}\text { ROS: } & \text { Reactive oxygen species } \\ \text { OS: } & \text { Oxidative stress } \\ \text { OSI: } & \text { Oxidative stress index } \\ \text { TAC: } & \text { Total antioxidant capacity } \\ \text { TOC: } & \text { Total oxidant capacity } \\ \text { EPA: } & \text { Endogenous peroxidase activity } \\ \text { MDA: } & \text { Malondialdehyde } \\ \text { MPO: } & \text { Myeloperoxidase } \\ \text { PPm: } & \text { Total polyphenols } \\ \text { ACTH: } & \text { Adrenocorticotropic hormone } \\ \text { hsCRP: } & \text { High-sensitivity c-reactive protein } \\ \text { IL-6: } & \text { Interleukin-6 } \\ \text { BDNF: } & \text { Brain-derived neurotrophic factor } \\ \text { SD: } & \text { Standard deviation } \\ \text { IQR: } & \text { Interquartile range } \\ \text { 95\% CI: } & \text { 95\% confidence interval } \\ \text { IQRs: } & \text { Interquartile ranges } \\ \text { CV: } & \text { Coefficient of variation } \\ \text { ICC: } & \text { Intraclass correlation coefficient } \\ \text { BMI: } & \text { Body mass index. }\end{array}$

\section{Conflicts of Interest}

The authors declare they have no competing interests that might be perceived to influence the results and discussion reported in this article-except W. Wonisch, who is a member of Omnignostica Ltd.

\section{Authors' Contributions}

Sieglinde Zelzer and Franz Tatzber contributed equally to this study.

\section{Acknowledgments}

The authors gratefully acknowledge the scientific advice and support of G. Reibnegger and S. Holasek. Language editing was done by Eugenia Lamont. This work is dedicated to my daughter Marion Zelzer (S. Z.)

\section{References}

[1] M. Breitenbach and P. Eckl, "Introduction to oxidative stress in biomedical and biological research," Biomolecules, vol. 5, no. 2, pp. 1169-1177, 2015.

[2] B. Halliwell, "Free radicals, reactive oxygen species and human disease: a critical evaluation with special reference to atherosclerosis," British Journal of Experimental Pathology, vol. 70, no. 6, pp. 737-757, 1989.

[3] S. E. Johnstone and S. B. Baylin, "Stress and the epigenetic landscape: a link to the pathobiology of human diseases?," Nature Reviews Genetics, vol. 11, no. 11, pp. 806-812, 2010.

[4] H. N. Siti, Y. Kamisah, and J. Kamsiah, "The role of oxidative stress, antioxidants and vascular inflammation in cardiovascular disease (a review)," Vascular Pharmacology, vol. 71, pp. 4056, 2015.

[5] N. S. Dhalla, R. M. Temsah, and T. Netticadan, "Role of oxidative stress in cardiovascular diseases," Journal of Hypertension, vol. 18, no. 6, pp. 655-673, 2000.

[6] G. Schippinger, W. Wonisch, P. M. Abuja, F. Fankhauser, B. M. Winklhofer-Roob, and G. Halwachs, "Lipid peroxidation and antioxidant status in professional American football players during competition," European Journal of Clinical Investigation, vol. 32, no. 9, pp. 686-692, 2002.

[7] G. Schippinger, F. Fankhauser, P. M. Abuja et al., "Competitive and seasonal oxidative stress in elite alpine ski racers," Scandinavian Journal of Medicine \& Science in Sports, vol. 19, no. 2, pp. 206-212, 2009.

[8] M. Antoncic-Svetina, D. Sentija, A. Cipak et al., "Ergometry induces systemic oxidative stress in healthy human subjects," The Tohoku Journal of Experimental Medicine, vol. 221, no. 1, pp. 43-48, 2010.

[9] H. Mangge, K. Becker, D. Fuchs, and J. M. Gostner, "Antioxidants, inflammation and cardiovascular disease," World Journal of Cardiology, vol. 6, no. 6, pp. 462-477, 2014.

[10] S. Hekimi, J. Lapointe, and Y. Wen, "Taking a "good" look at free radicals in the aging process," Trends in Cell Biology, vol. 21, no. 10, pp. 569-576, 2011.

[11] A. J. P. O. de Almeida, T. P. Ribeiro, and I. A. de Medeiros, "Aging: molecular pathways and implications on the cardiovascular system," Oxidative Medicine and Cellular Longevity, vol. 2017, Article ID 7941563, 19 pages, 2017.

[12] C. U. D. Stenfors, I. H. Jonsdottir, L. L. Magnusson Hanson, and T. Theorell, "Associations between systemic proinflammatory markers, cognitive function and cognitive complaints in a population-based sample of working adults," Journal of Psychosomatic Research, vol. 96, pp. 49-59, 2017.

[13] T. Ulas, H. Buyukhatipoglu, I. Kirhan et al., "Evaluation of oxidative stress parameters and metabolic activities of nurses 
working day and night shifts," Revista da Escola de Enfermagem da USP, vol. 47, no. 2, pp. 471-476, 2013.

[14] C. M. Corradi-Webster and A. M. P. Carvalho, "Dialogues in psychology and nursing in a time of shifting paradigms," Revista da Escola de Enfermagem da USP, vol. 45, no. 4, pp. 974-980, 2011.

[15] S. Zelzer, R. Oberreither, C. Bernecker, I. Stelzer, M. Truschnig-Wilders, and G. Fauler, "Measurement of total and free malondialdehyde by gas-chromatography mass spectrometry - comparison with high-performance liquid chromatography methology," Free Radical Research, vol. 47, no. 8, pp. 651-656, 2013.

[16] F. Tatzber, S. Griebenow, W. Wonisch, and R. Winkler, "Dual method for the determination of peroxidase activity and total peroxides-iodide leads to a significant increase of peroxidase activity in human sera," Analytical Biochemistry, vol. 316, no. 2, pp. 147-153, 2003.

[17] F. Tatzber, E. Pursch, U. Resch et al., "Cultivation and immortalization of human B-cells producing a human monoclonal IgM antibody binding to MDA-LDL: further evidence for formation of atherogenic MDA-LDL adducts in humans in vivo," Oxidative Medicine and Cellular Longevity, vol. 2017, Article ID 6047142, 7 pages, 2017.

[18] W. Wonisch, A. Falk, I. Sundl, B. M. Winklhofer-Roob, and M. Lindschinger, "Oxidative stress increases continuously with BMI and age with unfavourable profiles in males," The Aging Male, vol. 15, no. 3, pp. 159-165, 2012.

[19] P. Sutkowy, B. Augustynska, A. Wozniak, and A. Rakowski, "Physical exercise combined with whole-body cryotherapy in evaluating the level of lipid peroxidation products and other oxidant stress indicators in kayakers," Oxidative Medicine and Cellular Longevity, vol. 2014, Article ID 402631, 7 pages, 2014.

[20] A. E. Carrillo and A. D. Flouris, "Caloric restriction and longevity: effects of reduced body temperature," Ageing Research Reviews, vol. 10, no. 1, pp. 153-162, 2011.

[21] C. Nagata, T. Tamura, K. Wada et al., "Sleep duration, nightshift work, and the timing of meals and urinary levels of 8isoprostane and 6-sulfatoxymelatonin in Japanese women," Chronobiology International, vol. 34, no. 9, pp. 1187-1196, 2017.

[22] S. L. Ramey, N. R. Downing, W. D. Franke, Y. Perkhounkova, and M. H. Alasagheirin, "Relationships among stress measures, risk factors, and inflammatory biomarkers in law enforcement officers," Biological Research for Nursing, vol. 14, no. 1, pp. 16-26, 2012.

[23] C. J. Huang, H. E. Webb, M. C. Zourdos, and E. O. Acevedo, "Cardiovascular reactivity, stress, and physical activity," Frontiers in Physiology, vol. 4, p. 314, 2013.

[24] A. Sharifian, S. Farahani, P. Pasalar, M. Gharavi, and O. Aminian, "Shift work as an oxidative stressor," Journal of Circadian Rhythms, vol. 3, p. 15, 2005.

[25] S. D. Flanagan, W. H. DuPont, L. K. Caldwell et al., "The effects of a Korean ginseng, GINST15, on hypo-pituitaryadrenal and oxidative activity induced by intense work stress," Journal of Medicinal Food, vol. 21, no. 1, pp. 104-112, 2018.

[26] H. Mangge, K. L. Summers, A. Meinitzer et al., "Obesityrelated dysregulation of the tryptophan-kynurenine metabolism: role of age and parameters of the metabolic syndrome," Obesity, vol. 22, no. 1, pp. 195-201, 2014.
[27] A. L. López-López, H. B. Jaime, M. C. Escobar Villanueva, M. B. Padilla, G. V. Palacios, and F. J. A. Aguilar, "Chronic unpredictable mild stress generates oxidative stress and systemic inflammation in rats," Physiology \& Behavior, vol. 161, pp. 15-23, 2016.

[28] Z. Zimet, M. Bilban, M. Marc Malovrh et al., "8-Isoprostane as oxidative stress marker in coal mine workers," Biomedical and Environmental Sciences, vol. 29, no. 8, pp. 589-593, 2016.

[29] T. S. Lin, C. C. Wu, J. D. Wu, and C. H. Wei, "Oxidative DNA damage estimated by urinary 8-hydroxy-2'-deoxyguanosine and arsenic in glass production workers," Toxicology and Industrial Health, vol. 28, no. 6, pp. 513-521, 2012.

[30] A. Walker, A. McKune, S. Ferguson, D. B. Pyne, and B. Rattray, "Chronic occupational exposures can influence the rate of PTSD and depressive disorders in first responders and military personnel," Extreme Physiology \& Medicine, vol. 5, no. 1, p. 8, 2016 . 


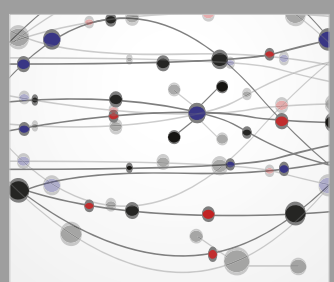

The Scientific World Journal
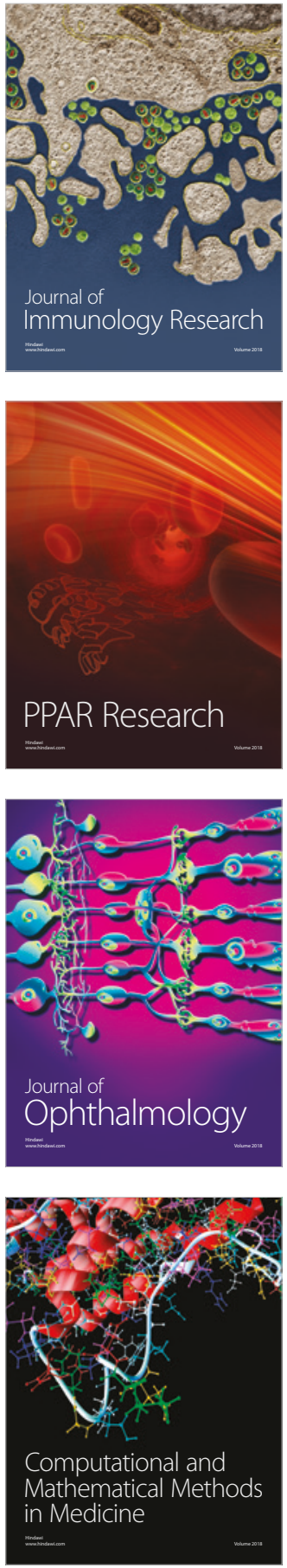

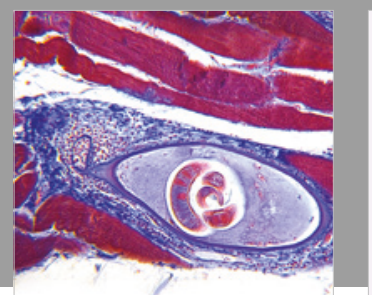

Gastroenterology Research and Practice

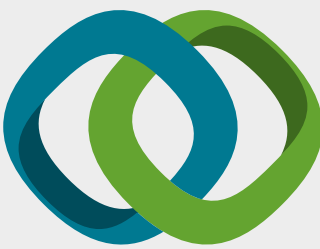

\section{Hindawi}

Submit your manuscripts at

www.hindawi.com
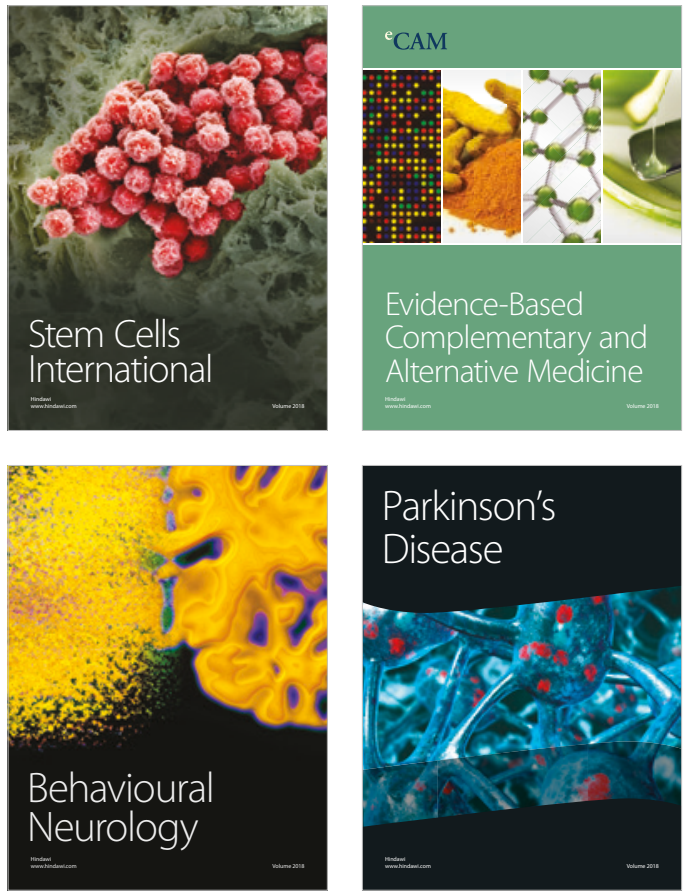

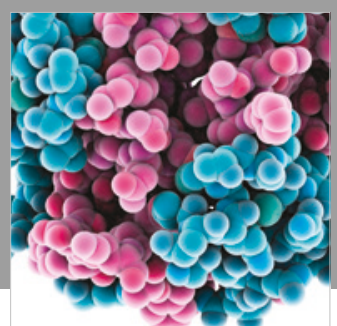

ournal of

Diabetes Research

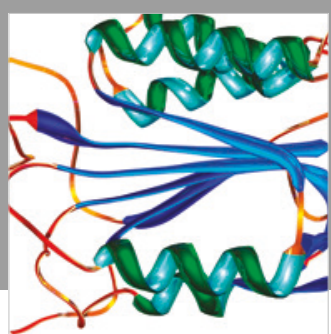

Disease Markers
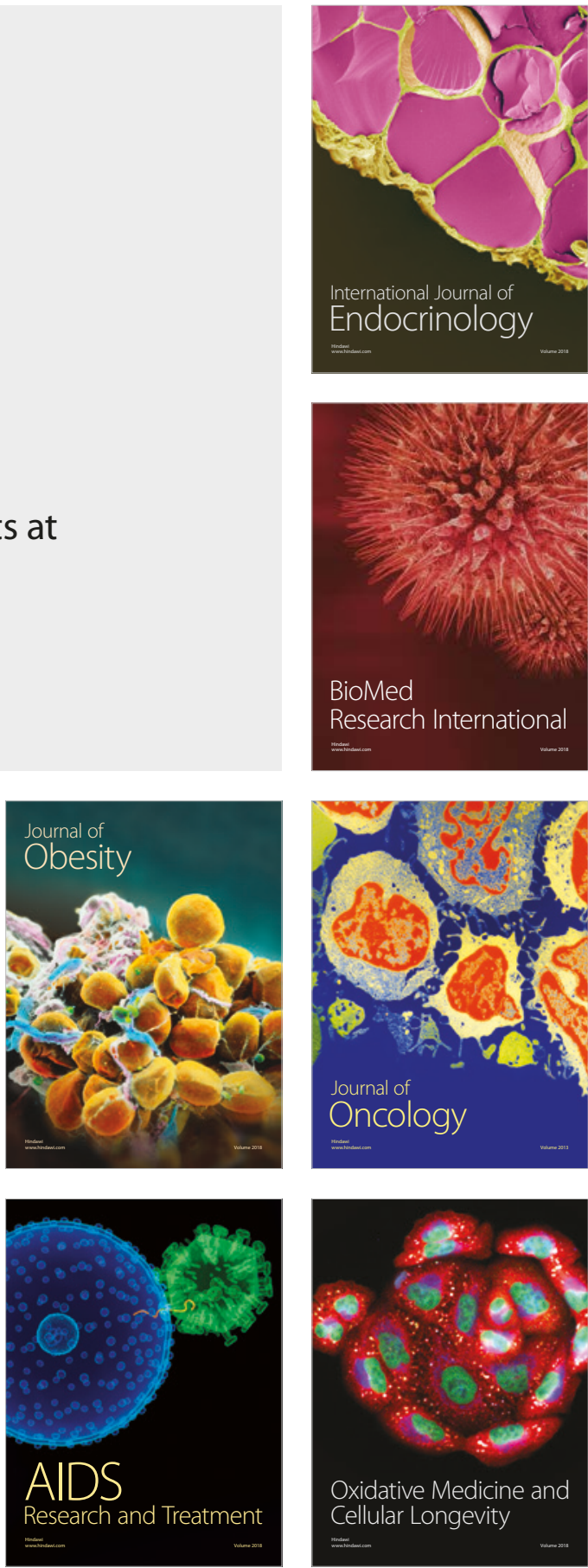